\section{Tetraparesia fláccida y desconexión del medio tras neumonía bilateral en un paciente alcohólico}

\section{Sr. Director:}

La afectación neurológica es frecuente en el paciente alcohólico. Así las convulsiones relacionadas con la ingesta excesiva o el síndrome de abstinencia constituyen la manifestación neurológica más frecuente, pero no podemos olvidar de la mayor propensión del alcohólico a desarrollar cuadros confusionales en relación con procesos sépticos, la mayor frecuencia de accidente cerebro vasculares, la encefalopatía hepática que complica el curso de la cirrosis alcohólica y, sobre todo, determinadas complicaciones más o menos específicas del alcohólico como la atrofia del vermis cerebeloso, la encefalopatía de Wernicke-Korsakoff, Marchiafava-Bignami, mielinolisis centropontina o la atrofia cortical precoz.

La enfermedad de Marchiafava-Bignami constituye una complicación temible puesto que lesiona el cuerpo calloso ocasionando desconexión con el medio y se asocia a lesiones de la sustancia blanca subcortical, siendo su pronóstico infausto. Su diagnóstico con frecuencia se retrasa por lo inespecífico de la clínica. Sin embargo la resonancia magnética permite el diagnóstico preciso al mostrar las lesiones características del cuerpo calloso como el caso que mostramos a continuación.

Paciente varón de 62 años fumador de 1 cajetilla día con dependencia alcohólica que es traído al Servicio de Urgencias tras haber presentado una crisis convulsiva. Al parecer llevaba unas dos semanas sin querer comer ni tomar líquidos (únicamente bebía vino), con pérdida ponderal y de fuerza en miembros inferiores. El día del ingreso lo encuentran inconsciente en la cama, con "espuma verde" por la boca y movimientos tónico clónicos generalizados. En el examen físico destaca hipotermia $\left(35,5^{\circ} \mathrm{C}\right)$; taquicardia (120 latidos por minuto); desnutrición importante; consciente; hipoventilación en hemitórax izquierdo; hepatomegalia de $2 \mathrm{~cm}$ dura, no masas palpables. Pupilas simétricas, isocóricas, lentamente reactivas. Moviliza las 4 extremidades.

Inicialmente se observa: hemoglobina 13,8 g/dl; Hematocrito 40,0\%; VCM 109,3 fl, plaquetopenia $60.000 \mathrm{~mm}^{3}$. Actividad de protrombina $42 \%$, GOT $53 \mathrm{U} / 1$, GPT $13 \mathrm{U} / 1$; bilirrubina total 1,7 mg/dl; CPK- NAC 199 U/l; proteínas 5,2 g/dl. Fósforo, magnesio, calcio, sodio y potasio dentro de la normalidad. Acidosis metabólica con pH 7,18, HCO3 10,2 mmol/1. acido láctico 6,2 $\mathrm{mmol} / \mathrm{l}, \mathrm{PCR}>90 \mathrm{mg} / \mathrm{l}$. Serología hepatitis B y C y HIV negativa. Alfafetoproteína: $2,3 \mathrm{ng} / \mathrm{ml}$; ferritina $2.000 \mathrm{ng} / \mathrm{ml}$. La radiografía de tórax inicial es irrelevante. El electrocardiograma demuestra una fibrilación auricular a 120 latidos por minutos. Se realizó tomografía computarizada (TAC) de cráneo donde se objetiva una importante atrofia cortical frontal, signos de atrofia cortico-subcortical y desmielinización periventricular así como en esplenio del cuerpo calloso. La ecografía abdominal mostró un hígado con masa sólida de 9 x 5,5 cm con pequeño nódulo satélite sugestiva de hepatocarcinoma.

En las horas posteriores a su ingreso presenta deterioro progresivo de la consciencia con Glasgow de 3-4, hipotensión arterial, fiebre, taquicardia e insuficiencia respiratoria que obliga a intubación orotraqueal, ventilación mecánica y soporte hemodinámico con aminas. El estudio radiológico evidenció la presencia de infiltrado pulmonar bilateral. Se diagnostica de shock séptico de origen pulmonar, síndrome de distress respiratorio y fallo multiorgánico, que tras tratamiento antibiótico mejora de forma lenta.

Tras la retirada de la sedo-relajación se constata tetraparesia fláccida y deterioro del sensorio con escasa conexión con el medio y nula respuesta a estímulos, por lo que se realiza punción lumbar, que es normal, y electroencefalograma, que presenta una actividad de fondo lentificada sin anomalías comiciales. Una nueva TAC no mostró cambios. En una RMN cerebral se objetiva desmielinización aguda del cuerpo calloso sugestiva de enfermedad de Marchiafava-Bignami (Fig. 1). Presenta complicaciones infecciosas nosocomiales con sobreinfección pulmonar por gérmenes gram negativos como Enterobacter cloacae, Acinetobacter baumannii, Serratia marcescens. El paciente fallece tras 20 días de ingreso.

La enfermedad de Marchiafava-Bignami es un trastorno infrecuente caracterizado por la desmielinización o necrosis del cuerpo calloso y la sustancia blanca subcortical que ocurre predominantemente en alcohólicos (3) aunque algunos casos han sido descritos en pacientes no alcohólicos, lo que sugiere que el alcohol, por sí mismo, no es el único responsable de la lesión. El curso de la enfermedad puede ser agudo, subagudo o crónico; se caracteriza por demencia, espasticidad, disartria e imposibilidad para la marcha. Los pacientes pueden evolucionar al coma y la muerte, sobrevivir algunos años en condiciones de demencia u ocasionalmente recuperarse (4).

Los casos referidos en la literatura basaban su diagnóstico en los hallazgo postmorten, pero la llegada del la tomografía compu- 


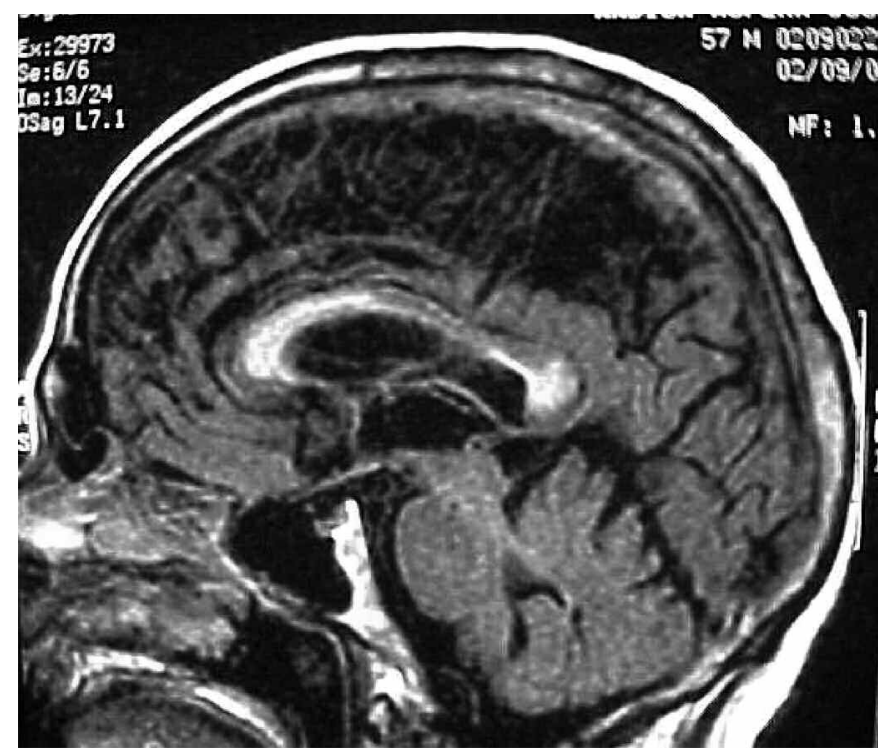

Fig. 1. Resonancia magnética (RM) de cráneo se observa una afectación completa del cuerpo calloso y las lesiones corticales.

tarizada y en especial del la resonancia magnética ha permitido establecer el diagnóstico in vivo (2).

Las imágenes de resonancia muestran una atrofia difusa del cuerpo calloso y necrosis focal, principalmente confinada a la rodilla, cuerpo y esplenio, con disminución de la señal de T1 e incremento de la señal de T2. Algunos autores sugieren que existen dos subtipos clínico-radiológicos: el Tipo A, caracterizado por mayor deterioro del nivel de conciencia y que presenta una captación T2 intensa en cuerpo calloso de forma temprana con evolución desfavorable, y el Tipo B que muestra un deterioro menor de la conciencia, lesiones parciales en el cuerpo calloso y una evolución más favorable (1). La afectación completa del cuerpo calloso y las lesiones corticales, como nuestro caso (Fig. $1)$, se asocian a una tasa elevada de mortalidad y secuelas cognitivas severas (6).

A. Pérez Ramírez, R. Ros, E. García-Valdecasas Campelo, J. A. López García ${ }^{1}$, E. González Reimers, F. Santolaria Fernández

Servicios de Medicina Interna y ${ }^{1}$ Resonancia Magnética. Hospital Universitario de Canarias

1. Brion S. Marchiafava-Bignami syndrome. In: Metabolic and Deficiency Diseases of the Nervous System, Part 2, Vinken PJ, Bruyn GW (Eds), North-Holland Publishing Company, Amsterdam 1976. p. 317.

2. Brion S. Marchiafava-Bignami syndrome. In: Metabolic and Deficiency Diseases of the Nervous System, Part 2, Vinken PJ, Bruyn GW (Eds), North-Holland Publishing Company, Amsterdam 1976. p. 317.

3. Chang KH, Cha SH, Han MH, Park SH, Nah DL, Hong JH. Marchiafava-Bignami disease: Serial changes in corpus callosum on MRI. Neuroradiol 1992; 34: 480-2.

4. Bourekas E, Varakis K, Bruns D. Lesions of the corpus callosum: MR imaging and differential considerations in adults and children. AJR AM J Roentgenol 2002; 179: 251-7.

5. Heinrich A, Runge U, Khaw AV. Clinicoradiologic subtypes of Marchiafava-Bignami disease. J Neurol 2004; 251: 1050-9.

6. Ménégon P, Sibon I, Pachai C, Orgogozo JM, Dousset V. Marchiafavabignami disease: Diffusion-corpus callosum and cortical lesions. Neurology 2005; 65: 475-7. 